\title{
Competitive-IgY- Enzyme Linked Immuno Sorbent Assay (CIgY-ELISA) to Detect the Cytokinins in Gerbera jamesonii Plantlets
}

\author{
Cleiton Mateus Sousa ${ }^{1 *}$, Ricardo Motta Miranda ${ }^{2}$ and Ronald Bastos Freire ${ }^{3}$ "In Memoriam” \\ ${ }^{I}$ Instituto Federal Goiano; Campus Ceres. Rod, GO 154, km 03, Zona Rural; 763000-000; Ceres - GO - Brasil. \\ ${ }^{2}$ Laboratório de Cultura de Tecidos Vegetais; Departamento de Fitotecnia; Instituto de Agronomia, Universidade \\ Federal Rural do Rio de Janeiro; BR 465 km 07; 23890-000; Seropédica - RJ - Brasil. ${ }^{3}$ Laboratório de \\ Imunoquímica Ambiental; Departamento de Tecnologia Ambiental; Universidade Federal Tecnológica do Paraná; \\ Av. Brasil, $n^{o}$ 4232; C.P.: 271; 85.884-000; Medianeira - PR - Brasil
}

\begin{abstract}
A competitive hyper-immune yolk Immunoglobulin Y - Enzyme Linked Immune Sorbent Assay (CIgY-ELISA), was developed as an alternative method to detect zeatin and 2ip in plantlets of gerbera. The endogenous level of hormones in the plantlets in vitro of gerbera with one or six weeks after replication was determined with competitive IgY-ELISA set to detect between 1 and 100 pmoles of plant hormone for each $1.0 \mathrm{~g}$ tissue. The plantlets of six weeks presented sprouts and root, while the plantlets of one week presented only sprouts. The CIgY-ELISA was set with high independent variables values of sensitivity/specificity of 96/89\% for zeatin and 94/78 \% for 2ip, with high values of reproducibility (up to $90 \%$ ) for both the cytokinins. Zeatin content varied from 2.2 to 2.8 pmoles. $g^{-1}$ and from 2.7 to 3.3 pmoles. $g^{-1}$ on the plantlet with one and six weeks, respectively. The 2ip content did not vary and was detected near the detection limit in all the assays. It was concluded that the observed capabilities of CIgY-ELISA were putative and the competitive assay was a highly robust and stable method, which could be used for the studies on plant physiology for endogenous cytokinins.
\end{abstract}

Key words: Determination of cytokinins, CIgY-ELISA, Zeatin, 2ip, micropropagated-Gerbera jamesonii

\section{INTRODUCTION}

The plant hormones determination, despite being considered an excellent alternative for understanding the plant physiological events (Centeno et al., 1997, Davies, 1995, Brault, Maldiney, 1999), has limited use in routine laboratory studies due to their complexity, expensiveness and time-consuming instrumental methods. There has been continuous effort to develop new Immunoassay techniques that estimate the concentration based on a comparison with known concentrations of a reference solution (Maldiney et al., 1986, Peres et al, 1997).

Immunoassays have been in use since the early 1960 's when radioimmunoassays were used to quantify insulin in plasma samples. Since then, immunoassays have been used to detect and quantify hundreds of molecules both native to living organisms, including hormones and foreign molecules, such as pharmaceuticals or persistent organic pollutants. These immunochemical

*Author for correspondence: sousacm@yahoo.com.br 
methods provide fast, sensitive, and cost effective analyses for a variety of environmental contaminants highlighting the great potential of immune assays in numerous fields such as biological, pharmaceutical or agricultural and food analysis (Green, Mason, 1987).

The molecules detected by the immunoassays vary widely in size, chemical and physical properties and biological activity. The immunoassays also have intrinsic qualities, such as precision, sensitivity and selectivity. During the last thirty years, several useful studies have been made on the plant hormone through these molecules by the means of immune assays such ELISA (Enzyme Linked Immuno Sorbent Assay) and RIA (Radioimmunoassay), respectively (Weiler, 1980; Weiler, 1981; Weiler, Wieczorek, 1981, Maldiney et al, 1986; Peres et al., 1997; Zhang, Ervin, 2008). Frequently, an antibody that recognizes one hapten will recognize other similar molecules, as is the case with the cyclodiene insecticide aldrin and other organochlorine pesticides (Green, Mason, 1987). For these cases, other separation techniques such as HPLC are required to distinguish between the specific molecules (Peres et al., 1997). While some immunoassays may be limited in distinguishing between the small differences in molecular structure within a family of compounds, they do have the distinct advantage of being highly selective even in the midst of much obscuring material, like humic acids, fulvic acids and petroleum spill. A sample that might require days of clean up in the can in some cases is checked in the field by immunoassay in about an hour without excessive cost or bulky equipment.

The anti-hapten polyclonal antibodies generation may also present variable capabilities from one batch to the other. Such limiting factor, besides the difficulties to maintain a pattern of strength and reproducibility for large periods of time, restrains the large-scale utilization of mammalian polyclonal-antibodies-based immune assays.

Recently, a highly efficient hyperimmune yolk immunoglobulins-based immunoenzymetric assay (capture IgY-ELISA) was described to detect the hapten Lupeol-acetate from Vernonia scorpioides (Freire et al., 2004). Although the strength of capture IgY-ELISA had been attested by its high reproducibility and a low internal variation, the detection limit was at the order of micromoles per gram of fresh weight tissue, which seemed to be excessively high when endogenous cytokinins content was taken in consideration.
A competitive IgY-ELISA (CIgY-ELISA), with the capability to detect femtogram of organic compounds (Zhang, Ervin, 2008), was exploited as an alternative immunochemical method to compare the level of zeatin and 2ip on in vitro plantlets of Gerbera jamesonii.

\section{MATERIAL AND METHODS}

\section{Laying Hens}

Four hens (Hyplantletwn) were housed at room temperature $\left(27 \pm 1{ }^{\circ} \mathrm{C}\right)$ in individual standard research cages. Birds received an adequate supply of clean potable water and feed ad libitum. They were kept according to the Brazilian Law for the Protection of Animals, following the guidelines in accordance with the proper welfare requirements, as approved by the Federal Rural University Animal-Research Ethics' Committee.

\section{Preparation of Conjugates}

Hapten-protein conjugates were prepared by the mixed anhydride method, as previously described (Pauillac et al, 2002) using the mixed anhydride coupling method of Erlanger et al. (1957), modified by Pauillac et al (1998). Briefly, 0.321 or $0.642 \mu \mathrm{mol}$ of phyto-hormone (zeatin-riboside or 2ip), dissolved in $20 \mu \mathrm{L}$ dry dimethyl sulfoxide (DMSO) was converted to a mixed anhydride (yield $>95 \%$ ) by adding a 10-fold molar excess of tributylamine and isobutyl chlorocarbonate. Two carriers were used throughout: bovine serum albumin (BSA) and ovalbumin (OVA), providing an initial hapten/protein molar ratio around 30: 1 . Conjugates were recovered by acetone precipitation, resuspended in $1.0 \mathrm{~mL}$ distilled water, filter-sterilized $(0.22 \mu \mathrm{m})$, dispensed into sterile tubes, then freeze-dried ovemight and stored at $-20{ }^{\circ} \mathrm{C}$ until use. Carrier haptenization was assessed spectrophotometrically in phosphate buffered saline solution (PBS - $0.01 \quad \mathrm{M}$ $\mathrm{KH}_{2} \mathrm{PO}_{4} / \mathrm{K}_{2} \mathrm{HPO}_{4}-150 \mathrm{mM} \mathrm{NaCl}, \mathrm{pH}$ 7.2).

\section{Immunization of hens and isolation of IgY from egg yolks}

Approximately $80 \mu \mathrm{g}$ of protein-phytohormone conjugate was re-suspended in $500 \mu \mathrm{PBS}$ and mixed with an equal volume of complete Freund's adjuvant (Behring Diagnostics, Sommerville, N.J.). Laying hens were immunized by injecting the antigen into the pectoral muscle. Two booster injections of $60 \mu \mathrm{g}$ antigen mixed with incomplete 
Freund's adjuvant were given two and four weeks later. The eggs were collected daily and stored at $4{ }^{\circ} \mathrm{C}$ for antibody extraction.

\section{Isolation of polyclonal chicken immunoglobulin $\mathbf{Y}$} The IgY-extraction from the egg yolk was separated from the egg white, washed with deionized water and placed in a funnel. The yolk volume in the yolks of the eggs was diluted with yolks itself in cold water $\left(4^{\circ} \mathrm{C}\right)$ at $1: 10$ and maintained at $4{ }^{\circ} \mathrm{C}$ for $24 \mathrm{~h}$ for precipitation. In the supernatant, the same volume of saturated solution of ammonium sulfate was added, maintained for $12 \mathrm{~h}$ as above. After centrifuging for 20 minutes $(2,800 \mathrm{x} \mathrm{g})$ at room temperature (RT), the pellet was discarded and the supernatant was supplemented with $0.5 \mathrm{~g}$ ammonium sulfate per milliliter of supernatant, mixed vigorously and incubated at RT for two hours. The resulting precipitate was dissolved with sodium phosphate buffer (100 mM, pH 7.6), re-precipitated twice with 70-95\% saturated ammonium sulfate, and desalted over a G-50 Sephadex column prior to centrifuging at $15,700 \times \mathrm{x}$ for 10 minutes. The pellet was resuspended in $2.0 \mathrm{ml}$ sodium phosphate buffer and stored at $-20{ }^{\circ} \mathrm{C}$. The purity of the $\operatorname{IgY}$ was established using the reducing and non-reducing polyacrylamide gel electrophoresis dialyzed.

\section{Plant material}

Gerbera jamesonii, var. Ornela plantlet was grown in multiplication MS medium containing $1 \mathrm{mgL}^{-1}$ BAP in a controlled growth chamber with $16 \mathrm{~h}$ light per day at $25 \pm 3{ }^{\circ} \mathrm{C}$ for the induction of proliferation of sprouts (Sousa, 2005). The plantlets with one week or six week culture were comparatively studied taking in consideration the endogenous level of cytokinins in the tissue. The CIgY-ELISA was carried out in 30 samples with four repetitions. For the limit dilution test, known concentrations of pure zeatin and 2ip were used as the gold standard for detecting both the cytokinins. Cytokinins quantification was done according to the phytohormone concentration that inhibited 50 $\%$ of the $\operatorname{IgY}$ capture assay of the conjugated cytokinin. Recovering systems, based in plantlet added of both the cytokinins were also done as a control for the reproducibility.

\section{Competitive IgY-ELISA (CIgY-ELISA)}

Phythormone concentration was determined using $1.0 \mathrm{~g}$ tissue of plantlet fragments which was diluted at 1:10 in methanol, macerated for 60 minutes at $4{ }^{\circ} \mathrm{C}$, filter-sterilized $(0.22 \mu \mathrm{m})$ and serially diluted at $1: 1 ; 1: 2 ; 1: 4$ and $1: 8$ in PBS plus $0.05 \%$ of Tween 20 (PBST). Each sample assayed was added to equal volume of 1:400 $\operatorname{IgY}$ anti-OVA-zeatin and 1:200 IgY anti-OVA-2ip, respectively. The neutralization step was carried out at $37{ }^{\circ} \mathrm{C}$ during 120 minutes before the CIgYELISA. The immunenzymatic assay was carried out by the addition of $100 \mu \mathrm{L}$ reaction-mixture to flat-bottomed microplates, previously sensitized with $100 \mathrm{mg}$ per $\mathrm{mL}$ of either BSA-zeatin or BSA -2ip. After 120 minutes at RT, the microplates were washed with PBST and submitted to an IgYcapture-ELISA. Then $100 \mu \mathrm{L}$ anti-IgY-peroxidase labeled goat antibodies (Sigma Co., St Louis), diluted at 1:20,000 in PBST, was added to each one reactive cavities. Microplates were gently mixed, incubated at RT for 120 minutes, washed and revealed with $200 \mu \mathrm{L}$ substrate-OPD for 20 minutes in the dark at RT. Reaction was stopped with $0.1 \mathrm{~N}$ sulfuric acid and optical densities were determined at $465 \mathrm{~nm}$. Plant hormone's concentration was calculated comparatively to their respective IC50 \% (Freire et al, 2004).

\section{Statistics}

The statistical significance of differences between each hormone IC50 \% was analyzed by using nonparametric Kruskal-Wallis test to compare the IgY-Capture-ELISA in the different plantlet extracts used.

\section{RESULTS AND DISCUSSION}

Cytokinins are molecules responsible for cell division and plant development due to their ubiquitous nature and high activity. Zeatin, ciszeatin, dihydro zeatin and 2ip are present in most plant tissues in higher plants. Proper application of cytokinins may be an effective approach to improve the performance of flowers. Although, the in vitro propagation of gerbera similarly to various other plants for reliable information about the production of plantlet in function of their endogenous cytokinin. Many of the developmental and physiological processes regulated by these plant hormones are of agronomic importance (Davies, 1995). 
Results were highly reproducible with a coefficient of variability of $1.5 \%$ for zeatin and 1.2 for $2 \mathrm{ip}$, respectively (Figures $1 \mathrm{~A}$ and $1 \mathrm{~B}$ ). The relative sensitivity/specificity was $1.1 \%$ for zeatin $(96 / 89 \%)$ and of $1.2 \%$ for 2ip (94/78 \%). Detection limits for each one of the cytokinins were from 0.7 to 100 pmoles. $\mathrm{g}^{-1}$ zeatin and from 1.0 to 100 pmoles. $\mathrm{g}^{-1} 2 \mathrm{ip}$.

CIgY-ELISA quantification, based on the IC50 \% of each cytokinin, showed zeatin content varying from 2.2 to 2.8 pmoles.g- ${ }^{1}$ in the freshly grown cultures, and from 2.7 to 3.3 pmoles.g- ${ }^{1}$ in the sixweek plantlet (Figure 2). The values of 2ip did not vary with the time, showing a mean concentration of approximately 1.0 pmol.g- ${ }^{1}$. All the evaluations were carried out during the rooting and elongation phases, starting from the first week of culture growth.
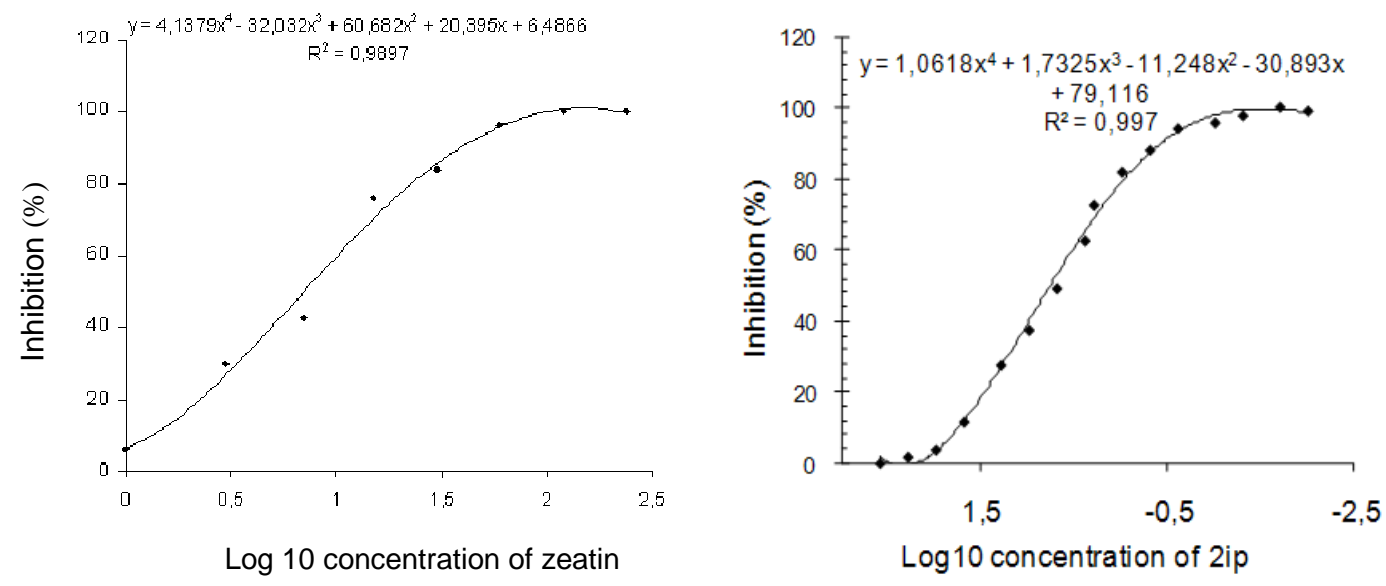

Figure 1 - Standard competitive IgY-ELISA for Zeatin (A) an 2ip (B) quantization in Gerbera jamesonii plantlets. Points are the median value of four replicates.

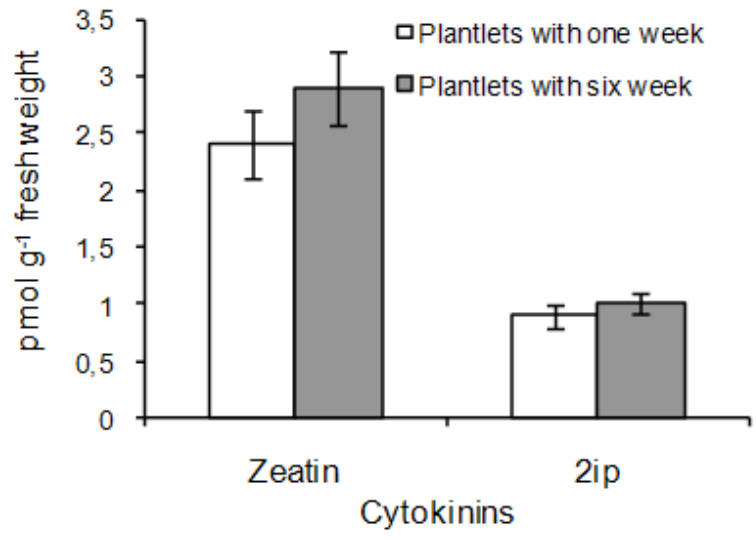

Figure 2 - Content of zeatin and isopentenyl adenine (2ip) in Gerbera jamesonii plantlets cultured for one (white bars) and six weeks (grey bars) in MS- medium added of $1 \mathrm{mg} \mathrm{L}^{-1}$ de BAP. Results are median values \pm standard errors of 15 samples, with four repetitions at each time interval. 
Zeatin level in $G$. jamesonii was at least two times higher than $2 \mathrm{ip}$ in all the samples evaluated, although this relationship became more intense in the plantlets which presented a clear development of pericyclic cells and an evident formation of new root primordia. In fact, an endogenous increase of cytokinins (free bases and riboside) might produce phenotypic changes that are associated to an increase in the chlorophyll and enhancement of senescence.

The majority the cytokinin added in the medium is consumed in first 20 days (Blakesley et al., 1991); subsequently, the differentiation and formation of sprouts occurs, acting as a new site of synthesis of auxin (Davies, 1995). This alters the hormonal balance in the tissue of plants and prompts various physiological events, including the differentiation of the roots.

The level of endogenous of 2ip was higher in zeatin in the callus of Medicago arborea and had inversion tendency with the time (Pintos et al., 2002). This was due to the $2 \mathrm{ip}$ obtained during the synthesis of zeatin (Haberer and Kieber, 2002; Mok and Mok, 2001). Figure 2 showed that in the plantlet of gerbera in vitro the level of zeatin was higher than the 2ip, independent of culture period of one or six weeks.

Although the activities of adenine derivatives were, until recently, difficult to assess, there a suggestion that in root development, the decrease in physiologically active cytokinins could be caused by the increased glucosylation with a concomitant stimulation of the initiation and growth of roots tips. Physiologically active adenine derivatives cytokinin was difficult to assess, probably as the function of an increased glucosylation, when a concomitant stimulation of the initiation and growth of root tips took place in the root development. It could be caused by the slower development due to cytokinin $O$ glucosylation and degradation $r$, thus prolonging the growth period as previously reported (Szekacs et al, 2000).

The low endogenous concentration of cytokinin presently detected could be related to the second step of root formation, corresponding to the first week culture, when elongation of young roots was already established. The higher zeatin concentration in the older plantlet might be explained by the reactivation of the pericyclic cells and the formation of new root primordia. It would be important to point out that the freshly one week old grown cultures did not show any evidence of the active rooting or lateral development, as commonly observed on the oldest six weeks plantlets (Sousa, 2005).

Despite of a slight argumentation with the time on the 2ip level, it was not significant and represented less than $50 \%$ of the zeatin endogenous independent of the rooting and tip development (Figure 2). These data corroborated with previous studies that attributed to a natural metabolic fate the enhancement of the zeatin endogenous with the concomitant decrease of 2ip (Pintos et al., 2002). Even though not being a general rule, as much the endogenous levels of zeatin grows, less 2ip will accumulate in the plantlet. Since 2ip is an intermediary precursor of cytokinins, it can be consumed at the rooting-reactivation step by the O-glucosylation and degradation.

\section{CONCLUSIONS}

CIgY-ELISA is an immunochemical technology which could be used in agronomic studies for a better understanding of aspects of the growth and development of the plants, and in their interactions with the environment and studies such as plant domestication. The IgY-based analysis presented here suggested that the changes in the plantlet architecture and development were consistent with the reduction of cytokinins. Consequently, there was a direct relationship between the plant hormone levels and the stage of development of growing plants, warranting further studies associating the behavior of the plants with the alterations in the hormonal level. Data concerned to the chlorophyll levels and development retention, hopefully, will support possible reflective increases in the cytokinins that might be used as an additional agronomic parameter to control the plant development, and growth and flowering, among other physiological events.

\section{REFERENCES}

Blakesley, D.; Lenton, J. R.; Horgan, R. (1991), Uptake and metabolism of 6-benzyladenine in shoot cultures of Gerbera jamesonii. Physiol. Plantarum. 81, 343348.

Brault, M.; Maldiney, R. (1999), Mechanisms of cytokinin action. Plant Physiol. Biochem. 37, 403412. 
Centeno, M. L.; Rodríguez, R.; Berros, B.; Rodrígues, A. (1997), Endogenous hormonal content and somatic embryogenic capacity of Corylus avellana L. cotyledons. Plant Cell Rep. 17, 139-144.

Davies, P. J. (1995), The plant hormones concept: concentration, sensitivity and transport. In: Davies, P. J. (Ed.) Plant hormones: physiology, biochemistry and molecular biology. Dorderecht, Kluwer Acad. Publi. p. 13 - 38.

Erlanger B. F.; Borek, F.; Beiser, S. M.; Lieberman, S. M. (1957), Steroidprotein conjugates I. Preparation and characterization of conjugates of bovine serum albumin with testosterone and with cortisone. J. Biol Chem. 228, 713-27.

Freire, R. B.; Freire, M. F. I.; Berbara, R. L. (2004), ELISA de captua com IgY para quantificação de Acetato de Lupeol em Vernonia scorpioides LAM. PERS (ASTERACEAE). Ciênc. Rural, Santa Maria. 34, 1069-1074.

Green J. A. and Manson M. M. (1987), Production of Polyclonal Antisera In "Immunochemical Protocols", Methods $m$ Molecular Biology, v. 80, $2^{\text {nd }}$ ed Edlted by J D Pound 0 Humana Press Inc , Totowa, NJ 500 p. 1-4.

Haberer, G.; Kieber, J. J. (2002), Cytokinins. New Insights into a Classic Phytohormone. Plant Physiol. 128, 354-362.

Maldiney, R.; Leroux, B.; Sabbagh, I.; Sotta, B.; Sossountzov, L.; Miginiac, E. (1986), A biotinavidin-based enzyme immunoassay to quantify three phytohormone: auxin, abscisic acid and zeatinriboside. J Immunol Meth. 90, 151-158.

Mok, D. W. S.; Mok, M. C. (2001), Cytokinin metabolism and action. Ann. Rev. Plant. Physiol. Plant. Mol. Biol. 52, 89-118,

Pauillac, S.; Naar, J.; Branaa, P.; Chinain, M. (1998), An improved method for the production of antibodies to lipophilic carboxylic hapten using small amount of hapten-carrier conjugate. J Immunol Meth. 220, 105 114.
Pauillac, S.; Naar, J.; Mouratou, B.; Guesdon, J. L. (2002), Application of a modified version of Habeeb's trinitrophenylation method for the characterization of hapten-protein conjugates in a reversed micellar medium. J Immunol Meth. 263, 75-83.

Peres, L. E. P.; Mercier, H.; Kerbauy, G. B.; Zaffari, G. R. (1997), Níveis endógenos de AIA, citocininas e ABA em uma orquídea acaule e uma bromélia sem raiz, determinados por HPLC e ELISA. R. Bras. Fisiol. Veg. 3, 169-176.

Pintos, B.; Martín, J. P.; Centeno, M. L.; Villalobos, N.; Guerra, H.; Martín, L. (2002), Endogenous cytokinin levels in embryogenic and nonembryogenic calli of Medicago arborea L. Plant Science. 163, 955-960.

Sousa, C. M. (2005), Otimização de protocolos para a propagação in vitro de Gérbera (Gerbera jamesonii). Dissertação (Mestrado em Fitotecnia), UFRRJ, Seropédica, p. 74.

Székács, A.; , Hegedus, G.; Tóbiás, I.; Pogány, M.; Barna, B. (2000), Immunoassays for plant cytokinins as tools for the assessment of environmental stress and disease resistance. Anal. chim. Acta. 421, 135146.

Weiler, E. W. (1981), Radioimmunoassay for pmolquantities of indole-3-acetic acid for use with highly stable [125 I] - and [3H]IAA derivatives as radiotracers. Planta. 153, 319-325.

Weiler, E. W. (1980), Radioimmunoassays for the differential and direct analysis of free and conjugate abscisic acid in plant extracts. Planta. 148, 262-272.

Weiler, E. W.; Wieczorek, U. (1981), Determination of femtomol quantities of gibberellic acid by radioimmunoassay. Planta. 152, 159-167.

Zhang, X.; Ervin, E. H. (2008), Impact of Seaweed Extract-Based Cytokinins and Zeatin Riboside on Creeping Bentgrass. Heat Tolerance. 48, 364-370.

Received: April 20, 2010; Revised: December 15, 2010; Accepted: May 22, 2011. 